\title{
Mechanism and numerical simulation of pressure stagnation during water jetting perforation
}

\author{
Huang Zhongwei, Li Gensheng*, Tian Shouceng, Shen Zhonghou and \\ Luo Hongbin
}

Key Laboratory of Petroleum Engineering, Ministry of Education, China University of Petroleum, Beijing 102249, China

\begin{abstract}
When perforating with an abrasive water jet, it is possible that the pressure in the hole (perforation) will be higher than that in the annulus because of water jet blasting against the hole wall, which also is the theoretical basis for the technology of hydro-jet fracturing. This paper analyzes the mechanism of generating pressure stagnation in water jet hole, and puts forward a new concept of hydroseal. Then, the distribution of pressure in the hole was simulated with the finite element method. The simulation results showed that the pressure in the hole was higher than that in the annulus. Also, the lower the annular pressure (confining pressure) and the higher the blasting pressure, the greater the pressure difference. An experiment indicated that the cement sample was lifted up under the pressure stagnation in the hole, which proved the finite element simulation results obviously.
\end{abstract}

Key words: Water jet, perforation, pressure stagnation, hydro-seal, mechanism

\section{Introduction}

When perforating with an abrasive water jet (AWJ), the AWJ will be pressurized through the tubing to the downhole tool's nozzle, exiting with high velocity to penetrate the casing and form a hole (perforation) in the formation. Compared with the conventional perforation, it can avoid decreasing the formation permeability because of the crushed zone existing in bullet perforation ( $\mathrm{Li}$ et al, 2000), enhancing the oil well production and fracturing efficiency. Some laboratory experiments have been done to optimize the fluid and the abrasive parameters in the AWJ perforation ( $\mathrm{Li}$ et al, 2002; 2004; 2006). Combining the AWJ perforation with fracturing, becomes a new technology, hydro-jet fracturing, in which packer can be eliminated, different intervals can be fractured, avoiding the risk of fracturing failure due to the packer sealing problem (East et al, 2005; McDaniel et al, 2004; Hoch et al, 2003; Rees et al, 2001; Surjaatmadja et al, 2007). The critical issue in this technology is that, at the blasting position, the pressure in the hole should be higher than that in the annulus (confining pressure). In the authors' viewpoint, it is the "hydro-seal" that brings about the pressure enhancement (pressure stagnation) in the hole to ensure the success of hydro-jet fracturing. In this paper, the finite element method and experimental data were used to analyze the pressure stagnation.

\section{Mechanism of pressure stagnation}

In blasting perforation, the AWJ is generally used to penetrate casing and formation. According to the previous

* Corresponding author. email: ligs@cup.edu.cn

Received October 15, 2007 research, the AWJ can form a spindle-shaped hole (Fig. 1) in the formation when the stand-off distance is smaller than $10 \mathrm{~mm}$ ( $\mathrm{Li}$ et al, 2002). When the high speed AWJ passes the casing wall and cement, and impacts the hole end, it has to return from the same path to the annulus. The hole in the casing wall, normally $10 \mathrm{~mm}$ diameter, not only is the way of the entering jet (red part in Fig. 1), but also provides the path for the returning fluid (green part in Fig. 1), which seemingly acts as a "seal" to increase the pressure in the hole (pressure stagnation), and consequentially fractures the formation. The finite element method is a practical way to calculate the pressure rise.

\section{Finite element simulation}

The effect of perforation parameters on fracturing is very complex ( $\mathrm{Li}$ et al, 2005). The perforation configuration in this simulation was established, according to the experimental results ( $\mathrm{Li}$ et al, 2002), as follows: Perforation depth $500 \mathrm{~mm}$, maximum diameter $50 \mathrm{~mm}$, the diameter of hole in the casing wall $10 \mathrm{~mm}$, and the perforation is spindle-shaped. Drawing the half part of the perforation (Fig. 2), we calculated the pressure distribution when changing the nozzle inlet pressure but fixing confining pressure and changing confining pressure but fixing nozzle inlet pressure, respectively.

\subsection{Distribution of pressure in the hole when changing nozzle inlet pressure but fixing confining pressure}

The confining pressure was set at $5 \mathrm{MPa}$, while the inlet pressure was set at $30,35,40,45$ and $50 \mathrm{MPa}$, respectively. Fig. 3 depicts the velocity vector near the nozzle exit when the inlet pressure was $30 \mathrm{MPa}$. This figure shows that the 


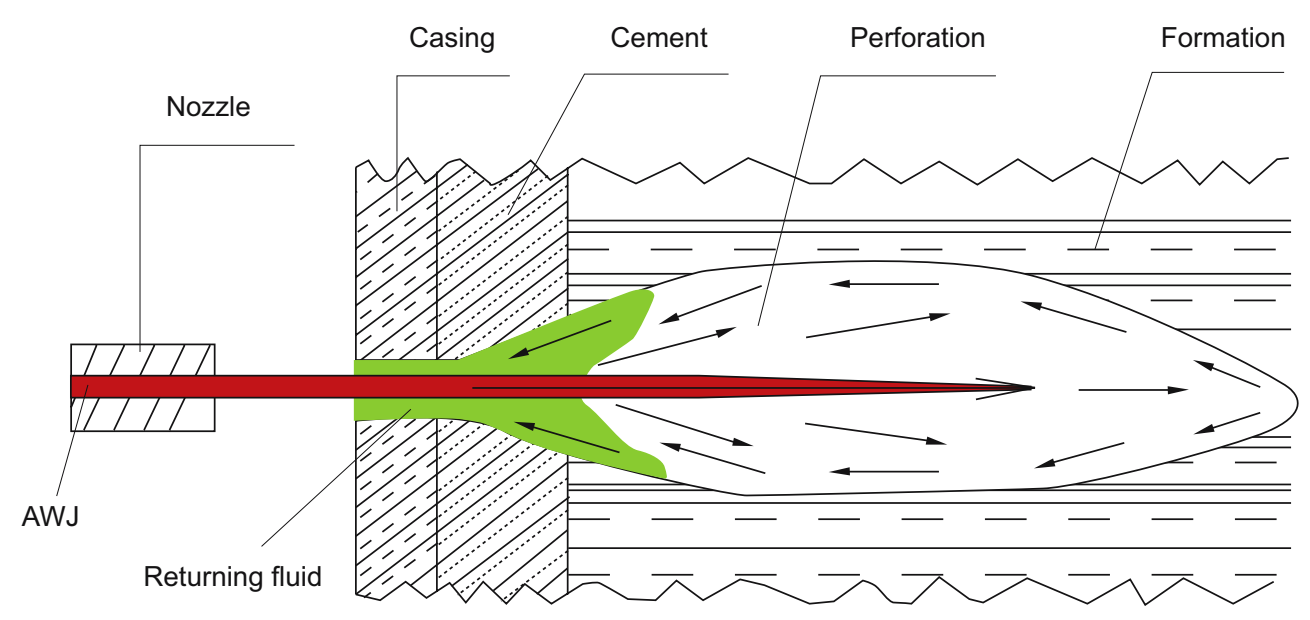

Fig. 1 Schematic view of the AWJ hole

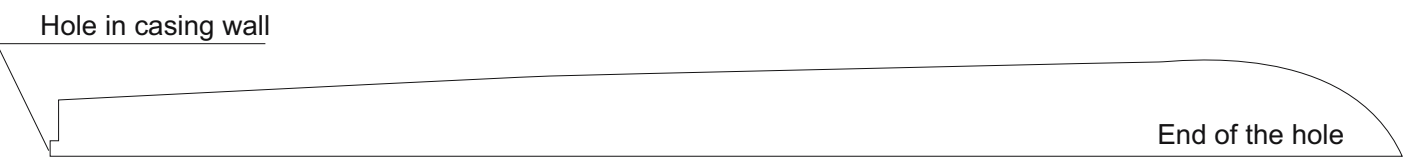

Fig. 2 Half profile of the hole

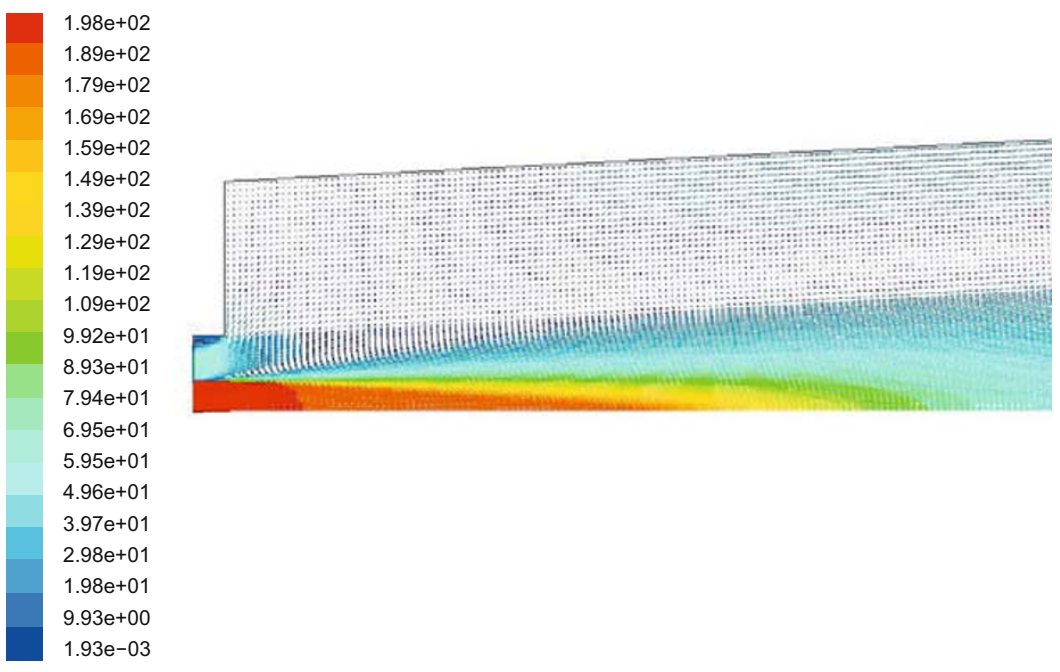

Fig. 3 Velocity vector near the nozzle exit

jet velocity attenuates rapidly after the jet exits the nozzle, decreasing from $198 \mathrm{~m} / \mathrm{s}$ to approximately $60 \mathrm{~m} / \mathrm{s}$ at the distance of $60 \mathrm{~mm}$. This phenomenon is different from conventional free jet (blasting into the air), which has a longer constant velocity area, with axial distance 5-50 times as long as the nozzle diameter. However in this calculated region, as shearing action exists between the entering and returning fluids, energy exchange will occur at the contact layer, resulting in rapid velocity attenuation.

Fig. 4 shows the distribution of pressure in the hole at different inlet pressures when the confining pressure was constant at $5 \mathrm{MPa}$. This indicates that after the stand-off distance of $0.1 \mathrm{~m}$ (25 times as great as the nozzle diameter), the pressure becomes stable, while at the end of the hole, the value goes up slightly. At an inlet pressure of $50 \mathrm{MPa}$, the pressure in the hole is approximately $12 \mathrm{MPa}, 7 \mathrm{MPa}$ higher than the confining pressure.

\subsection{Distribution of pressure in the hole when changing confining pressure but fixing nozzle inlet pressure}

When the inlet pressure was set at $35 \mathrm{MPa}$, the distribution of pressure in the hole was predicted at the confining pressures of 5, 10, 15 and $20 \mathrm{MPa}$, respectively. Fig. 5 shows 


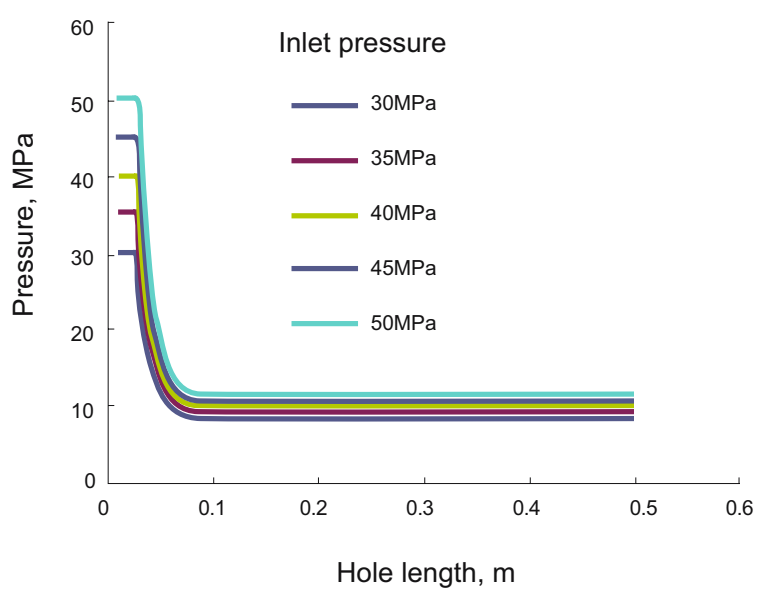

Fig. 4 Pressure distribution in the hole at different inlet pressures

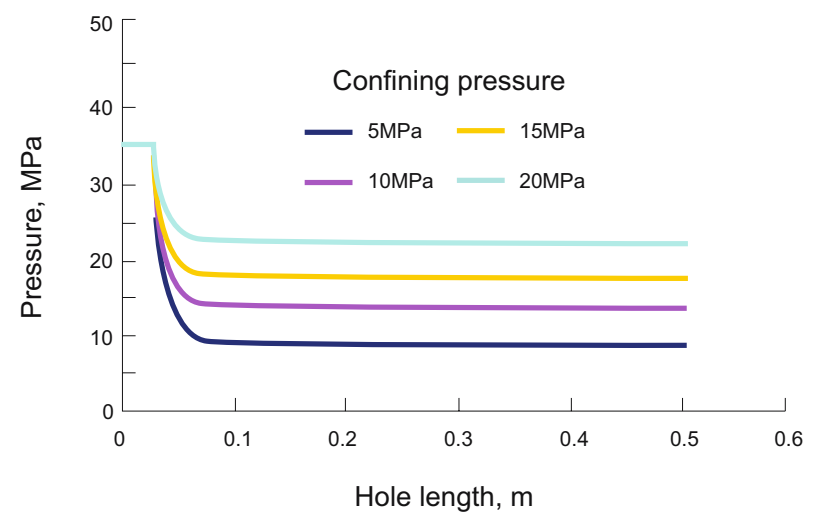

Fig. 5 Distribution of pressure in the perforation at different confining pressures

that the pressure in the hole would increase with the confining pressure. When the confining pressure was 5.0 $\mathrm{MPa}$, the pressure in the hole was 9.4 $\mathrm{MPa}, 4.4 \mathrm{MPa}$ higher than the confining pressure. Similarly, the pressure difference values were $3.7,2.9$ and $2.2 \mathrm{MPa}$ when the combinations were 10.0/13.7, 15.0/17.9 and 20.0/22.2 MPa, respectively. The above results show that, due to the formation of "hydro-seal", the pressure in the hole was always higher than the confining pressure. However, the higher the confining pressure, the smaller the difference, this is unfavorable to zone isolation during hydro-jet fracturing.

\subsection{Experiment of pressure rise in the hole}

Fig. 6 is the picture of the experiment performed to prove the pressure enhancement in the hole. The experimental conditions are as follows: a cement sample, with a diameter of $2.0 \mathrm{~m}$, a length of $1.2 \mathrm{~m}$, was enclosed with a thin steel sheet. A $51 / 2^{\prime \prime}$ casing was cemented in the cement sample. A blasting tool, with a diameter of $108 \mathrm{~mm}$ and four nozzles (diameter being 4, 5, 6 and $8 \mathrm{~mm}$, respectively) was used. Pump pressure was 45-50 $\mathrm{MPa}$, and corresponding flow rate was $2.2 \mathrm{~m}^{3} / \mathrm{min}$. During the experiment, the annulus between tubing and casing was open. From this picture, we could find that one side of the sample was lifted up by the high pressure in the perforation while blasting. This visual phenomenon could prove the occurrence of pressure enhancement (pressure

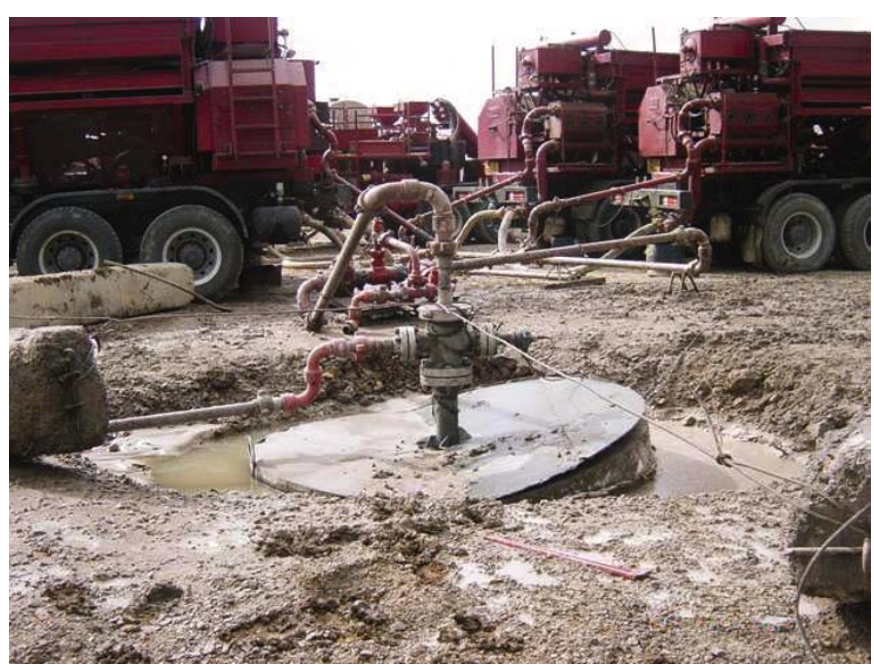

Fig. 6 Experiment of pressure stagnation in the perforation

stagnation) in the perforation, which was predicted previously by infinite element method.

\section{Conclusions}

1) During water jet blasting, the occurrence of pressure stagnation in the perforation was due to the formation of "hydro-seal", which also is the theoretical basis to realize hydro-jet fracturing.

2) The simulated results show that the lower the confining pressure and the higher the blasting pressure, the greater the pressure difference between perforation and annulus.

3) Higher confining pressure is unfavorable to enhance pressure stagnation in the perforation and to perform hydrojet fracturing in deeper wells.

4) In the experiment, the cement sample was lifted up on one side, which proved the occurrence of pressure stagnation in the perforation.

\section{Acknowledgements}

This work was financially supported by National Natural Science Foundation of China (No. 50774089) and Hightech Research and Development Program of China (No. 2007AA09Z315). The authors would like to thank them for their approval to publish.

\section{References}

East L, Rosato J, Farabee M, et al. New multiple interval fracture stimulation technique without packers. International Petroleum Technology Conference held in Doha, Qatar, 21-23 November, 2005 (SPE paper 10549)

Hoch O, Stromquist M, Love G, et al. Multiple precision hydraulic fractures of low-permeability horizontal openhole sandstone wells. SPE Annual Technical Conference and Exhibition held in Denver, Colorado, 5-8 October, 2003 (SPE paper 84163)

Li D C, Tang G H, Sun X B, et al. A study on perforation-crushed zone. Petroleum Exploration and Development. 2000. 27(5): 112-117 (in Chinese)

Li G S, Huang Z W, Niu J L, et al. Research advance of the influence of geostress and perforation parameters on hydraulic fracturing. Journal of the University of Petroleum, China (Edition of Natural Science). 
2005. 29(4): 136-142 (in Chinese)

Li G S, Liu L, Huang Z W, et al. Study of effect of hydraulic perforating on formation fracturing pressure. Journal of China University of Petroleum (Edition of Natural Science). 2006. 30(5): 42-45 (in Chinese)

Li G S, Niu J L, Liu Z K, et al. Experimental study on mechanisms of hydraulic sand blasting perforation for improvement of oil production. Journal of the University of Petroleum, China (Edition of Natural Science). 2002. 26(2): 31-35 (in Chinese)

Li G S, Niu J L, Song J, et al. Abrasive water jet perforation: An alternative approach to enhance oil production. Petroleum Science and Technology. 2004. 22(5\&6): 491-504

McDaniel B W, Willett R, East L, et al. Coiled-tubing deployment of hydrajet-fracturing technique enhances safety and flexibility, reduces job time. SPE Annual Technical Conference and Exhibition held in Houston, Texas, 26-29 September, 2004 (SPE paper 90543)

Rees M J, Khallad A, Cheng A, et al. Successful hydrajet acid squeeze and multifracture acid treatments in horizontal open holes using dynamic diversion process and downhole mixing. SPE Annual Technical Conference and Exhibition held in New Orleans, Louisiana, 30 September-3 October, 2001 (SPE paper 71692)

Surjaatmadja J B, Willett R, McDaniel B W, et al. Selective placement of fractures in horizontal wells in offshore Brazil demonstrates effectiveness of hydrajet stimulation process. SPE Drilling \& Completion. 2007. 22(2): 137-147 (SPE paper 90056)

(Edited by Sun Yanhua) 